\title{
Cegah Perilaku Kleptomania sejak Dini di SMK PGRI 2 Kota Kediri
}

\author{
Norma Risnasari ${ }^{1}$, Elysabet Herawati ${ }^{2}$, Dhian Ika Prihananto ${ }^{3}$, Muhammad \\ Mudzakkir $^{4}$, Ropita Oktaviani ${ }^{5}$, Yulla Yulfida Andarisma ${ }^{6}$ \\ ${ }^{1,2}$, Universitas Nusantara PGRI Kediri, Indonesia \\ normarisnasari@unpkediri.ac.id
}

\begin{abstract}
ABSTRAK
Kleptomania termasuk kelompok gangguan kepribadian borderline artinya terletak pada batas antara normal dan psikotik, yaitu kondisi yang termasuk dalam kelompok gangguan kendali impulsif, dimana penderita tidak dapat menahan diri untuk mengutil atau mencuri. Orang dengan kelainan ini terdorong untuk mencuri barang, umumnya barang yang tidak berharga, seperti pensil, permen, sisir, atau barang lainnya dan biasanya merasakan kelegaan atau kenikmatan setelah melakukan tindakan mencuri. Kegiatan penyuluhan kesehatan dilaksanakan pada tanggal 24 Januari 2019 diawali pre test dan diakhir dilakukan post test. Berdasarkan hasil pre test pada 60 siswa, maka sebanyak 19 siswa $(31,6 \%)$ menyatakan belum tahu tentang pengertian kleptomania, 50 siswa $(83,3 \%)$ menyatakan belum tahu penyebab kleptomania, 56 siswa $(93,3 \%)$ belum tahu ciri-ciri orang yang mengalami kleptomania, 54 siswa (90\%) belum tahu upaya pencegahan kleptomania, 60 siswa (100\%) tidak pernah melakukan kleptomania. Setelah dilakukan penyuluhan, maka kami memberikan soal yang sama dengan soal pre test. Dari hasil post test 60 siswa (100\%) menyatakan paham tentang pengertian, ciri-ciri dan upaya pencegahan kleptomania, 57 siswa $(95 \%)$ menyatakan paham penyebab kleptomania dan 13 siswa $(21,6 \%)$ pernah melakukan kleptomania. Penanganan yang merupakan pilihan utama untuk penderita kleptomania salah satunya dibawa ke psikolog, agar dilakukan terapi perilaku, yaitu serangkaian perilaku yang psikolog ciptakan untuk direkayasa, terapi tersebut tidak sekedar mengobati dari sisi pikirannya saja, namun juga sisi perasaannya, karena dorongan ini muncul dari perasaan, bukan pikiran. Keluarga dalam membantu proses penyembuhan sebaiknya ikut menciptakan suatu lingkungan atau suasana yang tidak memungkinkan bagi penderita klepto untuk kambuh lagi hasratnya.
\end{abstract}

Kata Kunci: Kleptomania, Terapi Perilaku, Gangguan Kepribadian

Received: October, 25, 2019

Revised: December 14, 2019

Accepted: February 11, 2020

This is an open-acces article distributed under the terms of the Creative Commons Attribution-ShareAlike 4.0 International License

\section{PENDAHULUAN}

Mencuri jelas perbuatan terlarang. Kasus kaum hawa yang menjadi pencuri ulung kian marak. Kleptomania atau yang disingkat klepto termasuk kelompok gangguan kepribadian borderline, artinya terletak pada batas antara normal dan psikotik adalah suatu kondisi yang termasuk ke dalam kelompok gangguan kendali impulsif, yaitu ketika penderita tidak dapat menahan diri untuk mengutil atau mencuri. Gangguan ini adalah salah satu gangguan kontrol impuls. Dengan kata lain, yang bermasalah adalah kemampuan mengontrol impulsnya. Disebut klepto jika individu tidak mampu 
mengendalikan diri melakukan dorongan untuk mencuri, bukannya ketertarikan terhadap barang yang dicuri. Sedangkan pada tindakan mencuri yang bukan klepto, tindakan mencuri dilakukan bukan karena ketidakmampuan menahan diri untuk mencuri, melainkan sebab-sebab lain, misalnya karena alasan ekonomi. (Anonim, 2009).

Orang dengan kelainan ini terdorong untuk mencuri barang-barang, umumnya barang-barang yang tidak berharga, seperti mencuri gula, permen, sisir, atau barang-barang lainnya. Penderita biasanya merasakan rasa tegang subjektif sebelum mencuri dan merasakan kelegaan atau kenikmatan setelah mereka melakukan tindakan mencuri tersebut. Tindakan ini harus dibedakan dari tindakan mencuri biasa yang biasanya didorong oleh motivasi keuntungan dan telah direncanakan sebelumnya. Meski jarang terjadi pada seseorang, namun penyakit mental ini membuat penderitanya terganggu secara emosional, sehingga malu untuk mencari pengobatan. Umumnya kleptomania terbentuk di masa remaja, namun ada juga yang muncul setelah dewasa. Pada orang dewasa, apalagi orang terkena kasus ini bisa berdampak pada rusaknya nama baik. Sensasi ketegangan yang dialami ketika mencuri lebih mendominasi mereka daripada hasrat memiliki benda tersebut. Secara finansial mereka mampu membeli benda-benda tersebut. Namun ketegangan yang mereka rasakan ketika melakukannya itulah sesungguhnya yang membuat mereka mengulang perbuatan tersebut. (Hasan, 2011). Penderita kleptomania kerap melakukan aksinya di tempat umum, seperti di warung atau toko, pusat perbelanjaan, namun sebagian ada juga yang mengutil dari rumah teman. Gangguan ini bisa menimpa anak-anak, remaja, atau dewasa. Meski jarang terjadi, kleptomania juga bisa dialami pada usia tua.

Menurut statistik, kleptomania atau gangguan kejiwaan yang mendorong seseorang untuk nekat 'ngutil' alias mencuri justru lebih banyak diderita oleh perempuan. Sebuah penelitian di Stanford University mengungkap, 62,5 persen penderita kleptomania adalah perempuan sementara 37,5 persen sisanya adalah laki-laki. Usia rata-rata saat didiagnosis positif mengidap gangguan kejiwaan ini adalah 45,6 tahun. Berdasarkan status perkawinannya, kleptomania lebih banyak diderita oleh laki-laki maupun perempuan yang sudah menikah atau punya pasangan yakni 47,5 persen. Sisanya adalah lajang sebanyak 27,5 persen serta duda atau janda yakni sebanyak 25 persen. Tidak ada perbedaan mencolok secara statistik terkait status pekerjaan para penderita kleptomania. Sebanyak 45 persen adalah pengangguran, terpaut sedikit dari karyawan tetap yakni 40 persen, sedangkan sisanya 15 persen adalah pekerja paruh waktu. Dikutip dari NCBI (2011), kleptomania merupakan gangguan kejiwaan yang menjangkiti 6 dari 1.000 orang di seluruh dunia. Di Amerika Serikat sendiri, jumlah penderitanya saat ini diperkirakan mencapai 1,2 juta orang.

Gangguan kleptomania menyebabkan seseorang tidak bisa menahan diri untuk mengambil sesuatu yang bukan haknya secara diam-diam. Tujuannya bukan untuk memperkaya diri, melainkan hanya untuk kepuasan karena biasanya barang-barang curian itu juga tidak pernah digunakan. Kleptomania dapat terjadi karena anak tidak pernah memperoleh pendidikan bahwa dorongan atau hasrat itu perlu dikendalikan dan bagaimana cara mengendalikannya. Mungkin saja ia tidak pernah merasa perlu melawan dorongan karena selalu terpenuhi keinginannya, mungkin juga ia anak yang tidak peduli dengan kebutuhan orang lain. Atau, bisa jadi karena komunikasi antar orang tua-anak tidak cukup baik sehingga anak tumbuh tanpa bimbingan. Beberapa anak yang mengambil barang orang lain secara tidak disadari menyampaikan "seruan minta tolong" untuk mendapat perhatian dari orang tua. Secara umum, gangguan klepto jarang terjadi, demikian halnya pada anak. Dengan demikian, dalam penggolongan gangguan jiwa, klepto tidak termasuk dalam gangguan perkembangan masa anak dan remaja. Namun, jika 
yang dimaksud adalah kebiasaan mengambil barang orang lain yang belum tentu karena masalah dorongan impuls, usia anak yang sudah memahami perilaku berkonsumsi (misalkan membeli) memungkinkan munculnya masalah ini.

Kelainan kleptomania cenderung lebih sering ditemui pada orang dewasa. Ketika anak sudah lebih besar, kira-kira 11 tahun ke atas, pikirannya sudah lebih berkembang dan lebih abstrak. Dia juga lebih mengerti hal yang boleh dan tidak boleh, termasuk tidak boleh mengambil barang yang bukan miliknya. Contohnya orang tua yang terlalu permisif, membolehkan anaknya melakukan hal apa pun sehingga si anak sulit membedakan hal yang boleh atau tidak boleh dilakukan. "Misalkan di rumah dia terbiasa mengambil barang orang tuanya tanpa permisi. Perilaku yang sama kemudian diterapkannya di sekolah". Orang tua yang otoriter dan serba melarang juga bisa menjadi penyebab anak memberontak. Larangan menyebabkan anak tidak punya kesempatan untuk mengetahui hal-hal yang belum diketahuinya. Padahal, sudah kodratnya anak-anak itu biasanya punya rasa ingin tahu yang besar. Bentuk penentangan kemudian diwujudkan dengan melakukan hal yang berlawanan dengan kehendak orang tuanya. Amati bahwa jika perilakunya itu sudah mengganggu fungsi dia sehari-hari, misalkan dalam keluarga atau di sekolah menyebabkan dia sulit berinteraksi, suka mengambil barang teman, fungsi belajarnya terganggu.

Penderita klepto, momen mengambil barang tersebut lebih pada saat dorongan atau hasrat muncul yang tak tertahankan alias impulsif. Penderita klepto susah mengontrol dorongan impulsif itu muncul. Meskipun dirinya sudah berkali-kali kepergok dan meminta maaf. Akan tetapi apabila dorongan itu datang kembali maka dia akan melakukannya lagi. Terapi paling baik memang dibawa kepada psikolog, agar bisa dilakukan terapi perilaku. Terapi perilaku adalah serangkaian perilaku yang psikolog ciptakan untuk direkayasa. Jadi, tidak sekedar mengobati dari sisi pikirannya saja, namun juga sisi perasaannya. Karena dorongan ini muncul dari perasaan, bukan pikiran. Keluarga dalam membantu proses penyembuhan tersebut adalah ikut menciptakan suatu lingkungan atau suasana yang tidak memungkinkan bagi penderita klepto untuk kambuh lagi hasratnya. (Sukarno, 2014).

\section{BAHAN DAN METODE}

Bahan atau materi pengabdian yang digunakan berupa power point dan leaflet tentang kleptomania. Metode yang digunakan berupa penyuluhan kesehatan kepada siswa di SMK PGRI 2 Kota Kediri dalam bentuk ceramah, diskusi dan tanya jawab. Penyuluhan meliputi konsep kleptomania, siswa dikenalkan pada pengertian, penyebab, gejala, ciri-ciri penderita kleptomania, pencegahan dan pengobatan. Evaluasi dilakukan dengan pre-test dan post-test sebelum dan sesudah dilakukan penyuluhan.

\section{HASIL}

Untuk hasil kegiatan diperoleh semua siswa mengikuti kegiatan penyuluhan kesehatan dari awal hingga akhir acara dengan tertib dan aktif. Dari kegiatan penyuluhan kesehatan diperoleh hasil sebagai berikut : 


\section{Journal of Community Engagement in Health}

http://jceh.org

ISSN: 2620-3758 (print); 2620-3766 (online)

https://doi.org/10.30994/jceh.v3i1.32

Vol.3 No.1. March 2020. Page.44-49

Tabel 1. Persentase hasil Pre Test dan Post Test Konsep Kleptomania

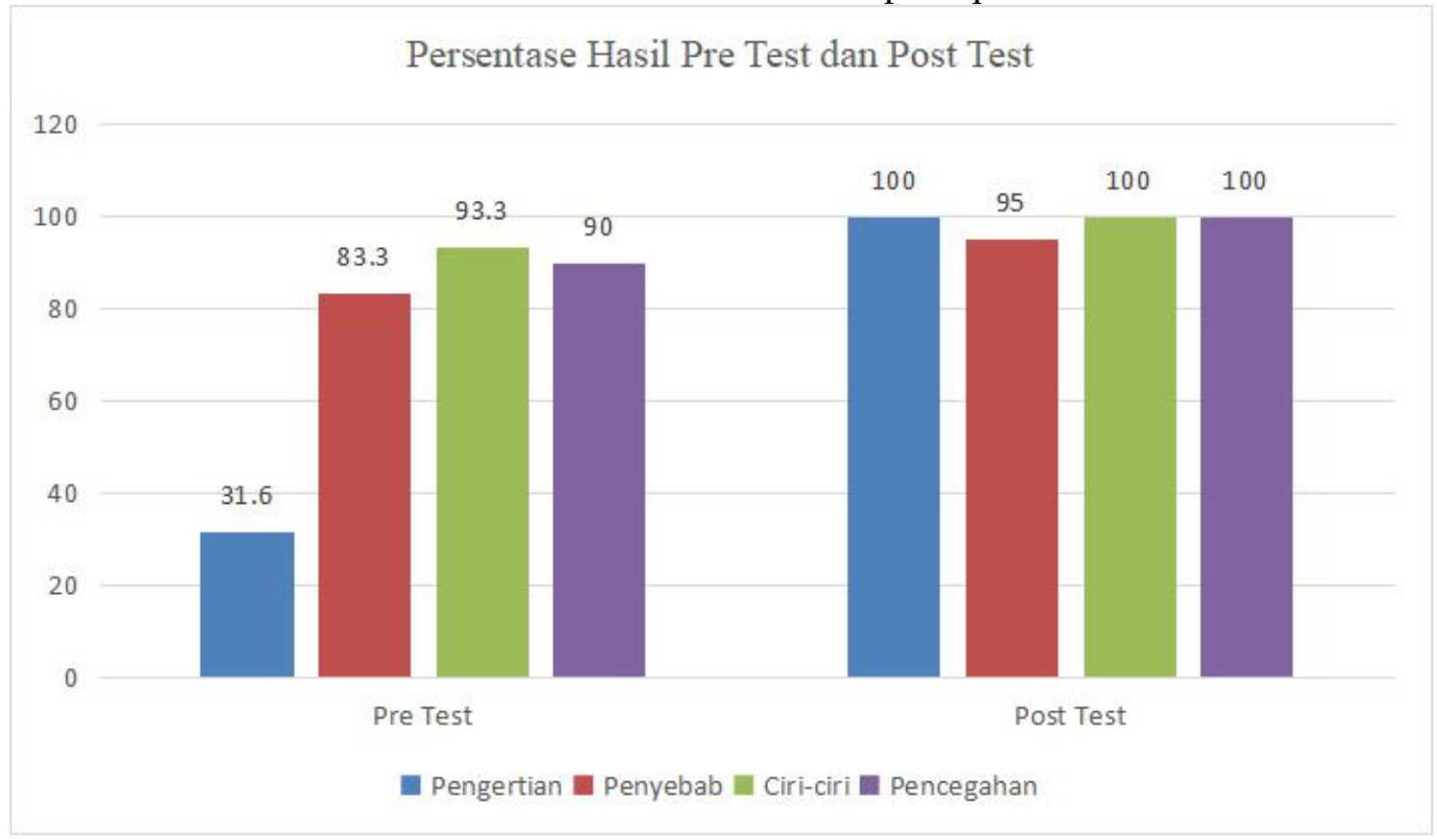

Berdasarkan tabel 1 diketahui bahwa hasil pre test 19 siswa $(31,6 \%)$ menyatakan belum tahu tentang pengertian kleptomania, 50 siswa $(83,3 \%)$ menyatakan belum tahu penyebab kleptomania, 56 siswa $(93,3 \%)$ belum tahu ciri-ciri orang yang mengalami kleptomania, 54 siswa (90\%) belum tahu upaya pencegahan kleptomania. Sedangkan hasil post test 60 siswa (100\%) menyatakan paham tentang pengertian, ciri-ciri dan upaya pencegahan kleptomania, 57 siswa (95\%) menyatakan paham penyebab kleptomania.

Tabel 2. Persentase hasil Pre Test dan Post Test Tidak Pernah atau Pernah Melakukan Kleptomania

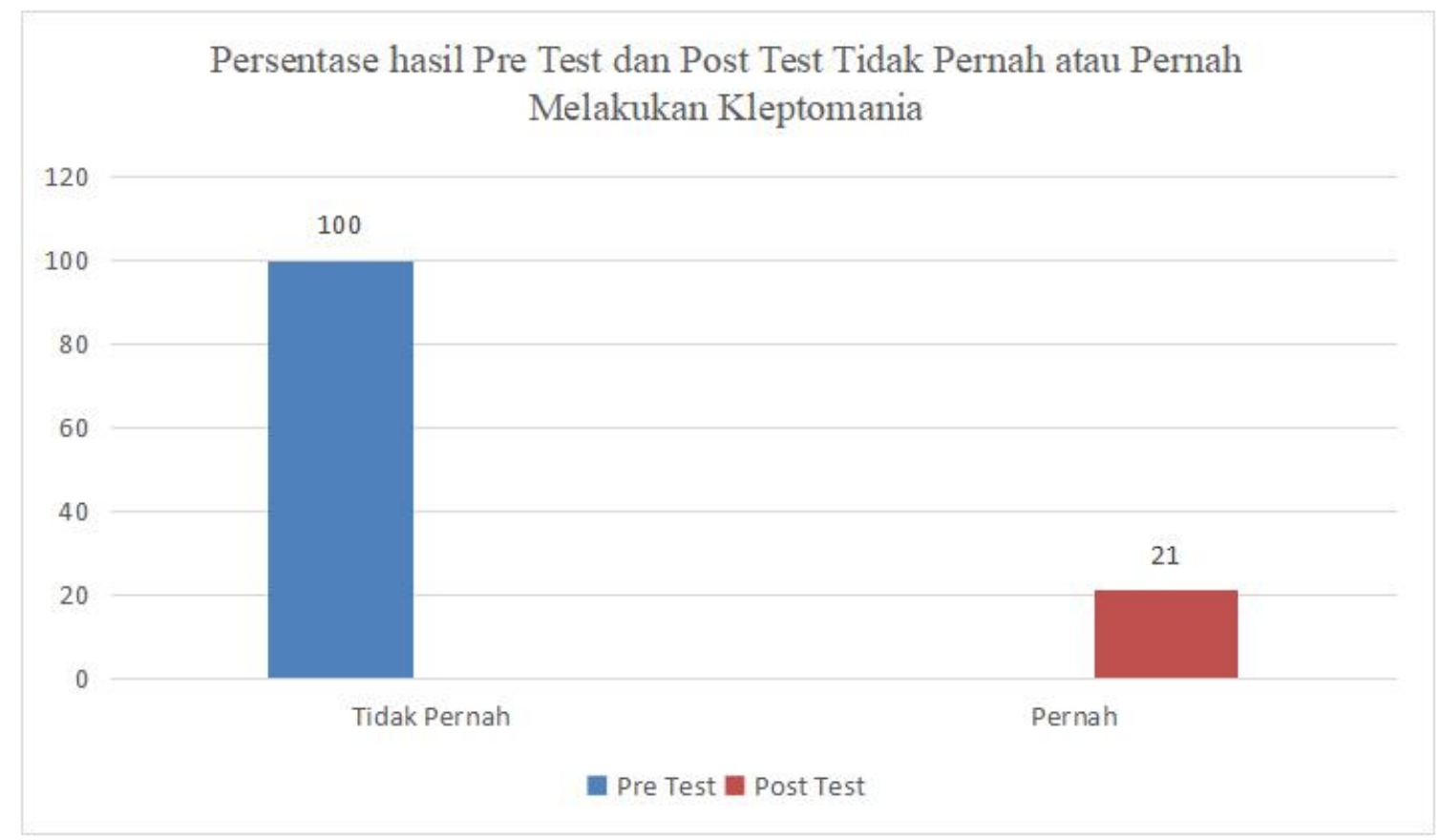


Berdasarkan tabel 2 diketahui bahwa hasil pre test 60 siswa (100\%) tidak pernah melakukan kleptomania, sedangkan hasil post test 13 siswa (21\%) pernah melakukan kleptomania.

\section{PEMBAHASAN}

Kegiatan Pengabdian Kepada Masyarakat dengan agenda penyuluhan kesehatan dilaksanakan di SMK PGRI 2 Kota Kediri pada tanggal 24 Januari 2019. Secara Keseluruhan, kegiatan ini berjalan dengan lancar. Penyuluhan kesehatan ini berupa penyampaian materi yang telah dibentuk dalam power point dan leaflet yang menarik mengenai konsep kleptomania antara lain pengertian, penyebab, gejala, ciri-ciri dan pencegahan kleptomania. Di dalam proses penyampaian materi para siswa aktif bertanya.

Hasil analisis pada tabel 1 mengatakan bahwa sebelum diberikan penyuluhan, pengetahuan siswa tentang kleptomania masih banyak yang belum tahu tentang pengertian, penyebab, gejala, ciri-ciri dan pencegahan hal ini terlihat dari hasil pre test.

Kemudian setelah dilakukan penyuluhan, ternyata ada perubahan yang sangat besar, sebagian besar siswa mengerti dan dapat menjawab dengan baik, hal ini terlihat dari hasil post test. Post test ini bertujuan untuk mengetahui peningkatan pengetahuan siswa setelah diberikan penyuluhan tentang kleptomania.

Sedangkan analisis pada tabel 2 mengatakan bahwa sebelumnya 60 siswa (100\%) tidak pernah melakukan kleptomania. Setelah diberikan penjelasan terkait dengan kleptomania mereka menjadi tahu dan 13 siswa $(21 \%)$ mengatakan pernah melakukan kleptomania. Hal ini dikarenakan mereka tidak punya uang untuk membeli barang yang diinginkan, coba-coba dan tidak ketahuan.

Menurut para siswa, penyuluhan kesehatan ini sangat bermanfaat karena dapat menambah pengetahuan mereka yang semula kurang tahu atau bahkan tidak tahu menjadi tahu. Hal lain yang diperlukan yaitu dukungan dari semua siswa serta guru bahkan orang tua (keluarga) untuk mencegah terjadinya kleptomania di lingkungan sekitar dengan cara membantu proses penyembuhan bagi penderita klepto supaya tidak kambuh lagi hasratnya. Penanganan lain yang merupakan pilihan utama untuk penderita kleptomania salah satunya dibawa ke psikolog, agar dilakukan terapi perilaku, yaitu serangkaian perilaku yang psikolog ciptakan untuk direkayasa, terapi tersebut tidak sekedar mengobati dari sisi pikirannya saja, namun juga sisi perasaannya, karena dorongan ini muncul dari perasaan, bukan pikiran. Secara umum, terapi tersebut membantu penderitanya mengidentifikasi perilaku itu tidak sehat dan menggantinya dengan yang sehat dan positif.

\section{KESIMPULAN}

Kegiatan pengabdian kepada masyarakat berupa penyuluhan kesehatan ini sebagai bentuk intervensi meningkatkan pengetahuan siswa tentang kleptomania di SMK PGRI 2 Kota Kediri. Antusiasme dari siswa selaku sasaran cukup baik. Hal tersebut terlihat dari awal hingga akhir kegiatan penyuluhan.

Berdasarkan hasil evaluasi diketahui bahwa pengetahuan siswa tentang kleptomania meningkat. Hal tersebut menjadi salah satu indikator keberhasilan kegiatan Pengabdian Kepada Masyarakat yang telah dilaksanakan. Selain itu, pihak sekolah SMK PGRI 2 Kota Kediri merasa senang menyambut kegiatan ini.

\section{REFERENSI}

Anonim. (2009). Kleptomania, Tanamkan Pengendalian Diri sejak Dini. 
https:/lifestyle.okezone.com/read/2009/06/02/196/225203/kleptomania-tanamkanpengendalian-diri-sejak-dini/large. diunduh tanggal 10 Oktober 2018 jam $09.20 \mathrm{WIB}$.

Anonim. (2011). Kenapa Orang Bisa Jadi Kleptomania?

https://health.detik.com/berita-detikhealth/d-1604390/kenapa-orang-bisa-jadikleptomania diunduh tanggal 10 Oktober 2018 jam 09.30 WIB.

Amelia, T., M. (2010). Kleptomania. http://anakkucingmengeonk. wordpress. com/2010 /03/27/ kleptomania/ diunduh tanggal 12 September 2018 jam 14.50 WIB.

Hasan, \& Hadi. (2011). Perilaku Kleptomania Di Sekolah https://addinalhadi.wordpress. com/ 2011/09/23/perilaku-kleptomania-di-sekolah/ diunduh tanggal 10 Oktober 2018 jam 09.30 WIB.

Latifah, F. (2011). Kleptomania. http://v3vizent.blogspot.com/2011/03/psikopat.html diunduh tanggal 12 September 2018 jam 14.55 WIB.

Setiaputri, \& Ariani, K. (2014). Mungkin Tak Disadari, Ini 4 Gejala Kleptomania yang Paling Umum. https://hellosehat.com/pusat-kesehatan/penyakit-mental/gejalakleptomania/ . Diunduh tanggal 12 September 2018 jam 14.25 WIB.

Sinseather. (2010). Penyebab, Ciri-ciri, Cara Mengatasi Kleptomania. http://archive.kaskus.us/thread/4869273 diunduh tanggal 12 September 2018 jam 15.00 WIB.

Sukarno, \& Ady, P. (2104). Ini Perbedaan Kleptomania Dengan Pencuri. http://ifestyle.bisnis.com/read/20140204/236/201088/ini-perbedaan-kleptomaniadengan-pencuri diunduh tanggal 12 September 2018 jam 14.30 WIB. Willy, Tjin. Kleptomania. https://www.alodokter.com/kleptomania diunduh tanggal 12 September 2018 jam 14.20 WIB 